\title{
Outcome of Myomectomy for Urinary Complications During the Second Trimenon of Pregnancy: 2 Cases Reports at the University Teaching Hospital of Angre / Abidjan
}

\author{
Koffi Soh Victor*, Adjoby Roland, Effoh Ndrin Denis, Kouakou-Kouraogo Ramata, Akobé Privat, \\ Soumahoro Zingbe Gondo, Loba Okoin Paul José, Gbary-Lagaud Eléonore
}

Teaching Hospital Center of Angre, Mother and Child Department, Felix Houphouet Boigny University, Abidjan, Cote d'Ivoire

\author{
Email address: \\ dockoffisoh@gmail.com (K. S. Victor) \\ *Corresponding author
}

\section{To cite this article:}

Koffi Soh Victor, Adjoby Roland, Effoh Ndrin Denis, Kouakou-Kouraogo Ramata, Akobé Privat, Soumahoro Zingbe Gondo, Loba Okoin Paul José, Gbary-Lagaud Eléonore. Outcome of Myomectomy for Urinary Complications During the Second Trimenon of Pregnancy: 2 Cases Reports at the University Teaching Hospital of Angre / Abidjan. Journal of Gynecology and Obstetrics. Vol. 9, No. 4, 2021 , pp. $112-115$. doi: $10.11648 /$ j.jgo.20210904.13

Received: July 14, 2021; Accepted: July 24, 2021; Published: August 2, 2021

\begin{abstract}
Uterine myomas are observed in about 3-12\% of pregnant women. These uterine fibroids can affect the outcome of pregnancy. There is an increased risk of spontaneous abortion, irregular fetal presentation, aseptic necrosis, placenta previa, premature birth, caesarean section, peripartum hemorrhage and also compression of nearby organs. Although myomectomy during pregnancy is not recommended, some emergency situations lead to retain this surgical indication. The authors report 2 cases of voluminous uterine myomas (FIGO type VI) that caused mechanical compression of the urinary tract with ureterohydronephrosis during the second trimenon of pregnancy. In our first clinical observation, the presence of fibroid was associated with severe bilateral ureterohydronephrosis, myomectomy was essential before the evolutionary risk towards renal failure. In our reported second case, there was no pain but acute retention of urine that required bladder catheterization. This retention was associated with sub-occlusive symptoms with stopping the materials for two weeks without gas. They benefited from a laparotomic myomectomy before term, with a favourable outcome for the mother and the child. The myomectomy during pregnancy remains exceptional and the evolutionary modalities are unpredictable with an increased risk of haemorrhage which can darken the obstetric prognosis, or even the vital one of the mother-child couple. Close prenatal monitoring is still necessary after the myomectomy.
\end{abstract}

Keywords: Myomectomy, Pregnancy, Ureterohydronephrosis, Prognosis

\section{Introduction}

Uterine myomas are the most common uterine pathology in the black race, making them the first tumour association during pregnancy. They are observed in about $3-12 \%$ of pregnant women. These uterine fibroids can affect the outcome of pregnancy $[1,2]$. In most cases, surgical abstention is required during pregnancy. In some situations, such as abdominal pain and the compression of nearby organs, it can be a therapeutic emergency [3]. The interest of this observation is to report the outcome of a necessity myomectomy during urinary complications in the second trimenon of pregnancy due to the mechanical compression of a voluminous uterine myoma.

\section{Observation 1}

This is AC, 33 years old, G2P0 ( 1 spontaneous miscarriage), student, referred for pregnancy of 19 weeks of amenorrhea (WA) on polymyomatous uterus with a renal repercussion at the Teaching Hospital of Angre in Abidjan. The patient had presented for one month intense pelvial pain not calmed by usual analgesics associated with urinary signs type pollakiuria. In its history, an indication of myomectomy was proposed 2 years ago following a spontaneous miscarriage. The patient was reportedly lost to follow-up. The examination on 
admission concluded to necrotic fibroids on progressive pregnancy of 19 WA according to the date of the last menses associated with abdominal distension and severe bilateral ureterohydronephrosis on abdominal ultrasound. In front of this clinical picture, an indication of myomectomy by laparotomy on pregnancy was retained. The pre-operative check-up was normal, including renal function. During surgery it was a large sessile sub-serous fundic myoma with a broad base (type VI according to FIGO) of $30 \mathrm{~cm} \mathrm{X} 25 \mathrm{~cm}$ on a gravid uterus of size 18-19 WA (Figure 1). Myomectomy is performed under general anesthesia and antispasmodic infusion and non-steroidal anti-inflammatory injection (Figures 2, 3 and 4). Blood loss was estimated at $400 \mathrm{cc}$, partially compensated by a $300 \mathrm{cc}$ transfusion of erythrocyte concentrate. Post-operative hemoglobin control was $7.5 \mathrm{~g} / \mathrm{dl}$. The procedures were simple with stable hemodynamic constants. An abdominal control ultrasound showed a live fetus and residual hemoperitoneum. The patient was discharged on D15 post-operative. The patient gave birth by caesarean section to a healthy eutrophic fetus (3000g, Apgar 8-9 in $5 \mathrm{~min}$ ) at 37 weeks of amenorrhea.

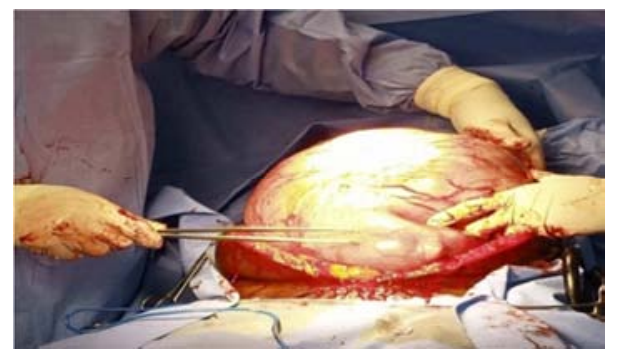

Figure 1. Surgical view after laparotomy of uterine fibroid.

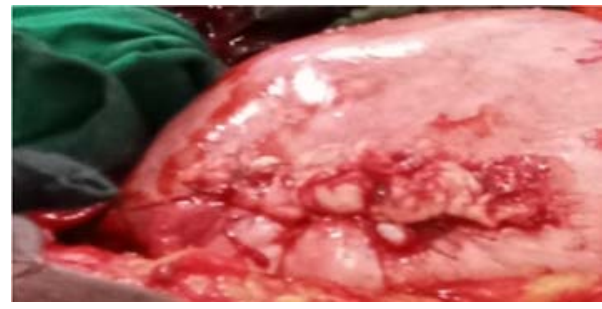

Figure 2. Uterine anterior face after hysterorrhaphy.

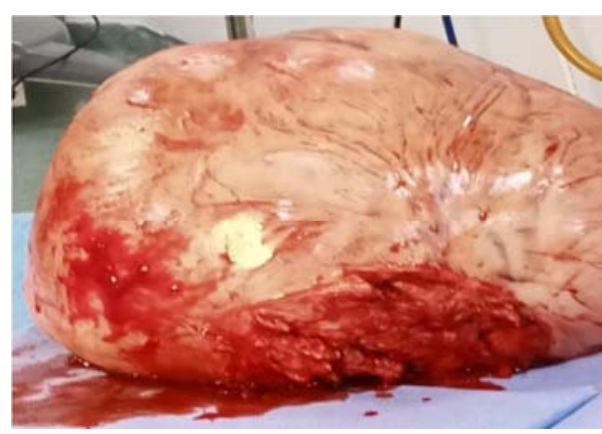

Figure 3. Voluminous fibroma after enucleation.

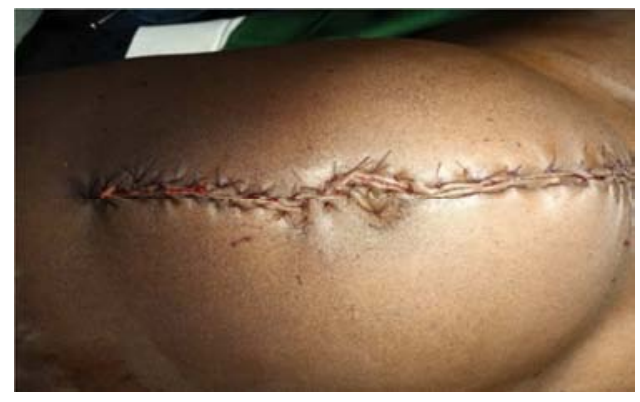

Figure 4. Post-operative parietal closure.

\section{Observation 2}

34-year-old patient, G4P1 with a seven-year-old child, two miscarriages. She had beeb reffered to us by the urology department for pelvic mass of gynecological origin after an acute retention of urine. The onset dates back to about one month with the occurrence of dysuria-like urinary disorders associated with constipation and abdominal pain in the form of tenesmus plus a febricule. The patient was relieved by an enema with Normacol ${ }^{\circledR}$ (Sodium dihydrogenophosphate dihydrate). But given the occurrence of acute retention of urine and digestive disorders becoming more and more persistent despite medical treatment, she consults the urology department where a urinary catheter was placed. On general examination, we note a good general condition with normal hemodynamic constants. The physical examination revealed a bloated abdomen with mild tympanism associated with a pelvic mass adjacent to a pregnant uterus estimated at 17 weeks of amenorrhea at the vaginal touch. The rectal touch objectified a voluminous hard multi-nodular non-hemorrhagic mass filling the Douglas sack ass. Before these signs, an ultrasound was requested which showed a progressive mono-fetal pregnancy of 17 weeks of ultrasound age on myomatous uterus of which a voluminous myoma of $19.4 \mathrm{~cm}$ $\mathrm{x} 10.4 \mathrm{~cm}$ interstitial dome under serous with right hydronephrosis beginner. Laparotomy was indicated after two weeks of procrastination.

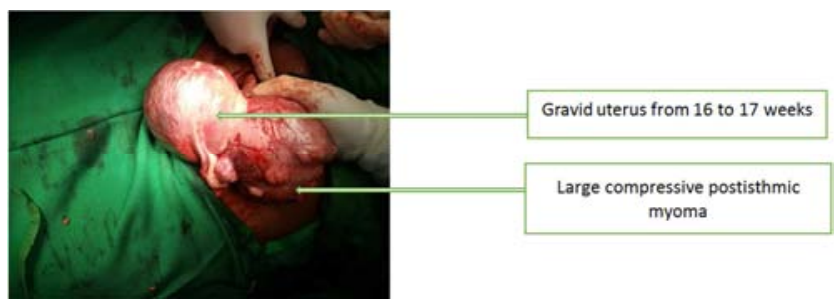

Figure 5. Large postisthmic fibroid on 17-week pregnancy.

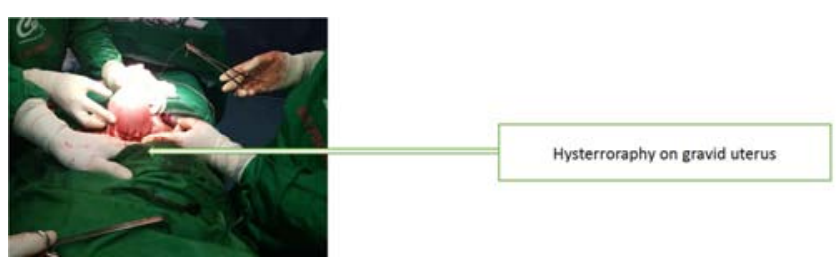

Figure 6. Gravid uterus after myomectomy. 


\section{Discussion}

The most frequently reported obstetric complications related to fibroids are: increased rate of spontaneous miscarriages in women with submucosal or intramural fibroids, aseptic necrobiosis, placentation disorders and irregular presentations. A higher rate of cesarean section is observed in pregnant women with fibroids [2, 4]. Myomectomy before the term of an active pregnancy is a problem: To observe an expectation until the end of pregnancy or have a interventionist attitude.

The management of mechanical complications related to the volumetric increase in fibroids is poorly described. Indeed, for years, the risk of hemorrhage led caregivers not to perform myomectomy during pregnancy. The current data is rather reassuring. In the literature, most of the removed myomas were pedicled subserosal or subserosal and fundal. Laparotomy was the main surgical approach (78.4\%), however, laparoscopic and vaginal operations have also been reported [4]. Studies by some authors such as Celik and Lopes $[5,6]$ have shown that only $10 \%$ of pregnant women with myoma suffer from complications related to the presence of these tumors. No study shows significant bleeding differences between myomectomy during cesarean section and cesarean section alone or myomectomy alone [2, 4, 7]. Most authors agree that symptomatic myomas can be treated surgically if needed [8]. In our first clinical observation, myomectomy was essential before the evolutionary risk towards renal failure. However, because of the high risk of myomectomy hemorrhages during pregnancy sometimes ending in hemostasis hysterectomy [5], some authors such as Lopes and colleagues [6] would opt for expectancy.

According to Swandinata [9] and Lolis [10] the most common and feared complication that may require myomectomy is severe abdominal pain that does not respond to medical treatment. This severe abdominal pain is due to twisting of pedunculated subserosal myomas or degeneration. It has been reported that if symptoms persist after $72 \mathrm{~h}$ of treatment, then surgery should be considered $[9,11]$.

In our reported second case, there was no pain but acute retention of urine that required bladder catheterization. This retention was associated with sub-occlusive symptoms with stopping the materials for two weeks without gas. The same is true for the work of Farshad [12], whose indication for operation was motivated by abdominal pain associated with subacute intestinal obstruction. In Barinov's study, the selected patients were between 18 and 45 years old and had large uterine fibroids $(\geq 8 \mathrm{~cm}$ ) diagnosed in the first trimester of pregnancy. These large uterine fibroids during pregnancy were associated with a threat of miscarriage in $46.4 \%$ of women and pain in nearly $40 \%$ of women. Myomectomy during pregnancy has been performed in 55 out of 120 women [13]. Some situations require emergency myomectomies, before the 3rd trimester of pregnancy, namely abdominal pain not responding to medical treatment $[4,12]$, compression of organs such as urinary tract, large vessels with risk of thrombophlebitis and nerve trunks due to large fibroids.
The long-term morbidity of myomectomy during pregnancy is not sufficiently studied but does not appear higher than expected for fertility and complications during pregnancy. Some patients received myomectomy on unknown pregnancies with a favourable outcome $[4,14,15]$. The usual complications observed with post-operative adhesions, in $90 \%$ of cases according to Tulandi [16]. In the literature, however, the achievement of myomectomy during pregnancy is not recommended by most scholarly societies. However, based on limited published data, myomectomy during pregnancy appears to be a safe procedure [4, 17]. Strict prenatal follow-up with obstetric ultrasound and close appointments, can be combined with a prophylactic caesarean proposed early to prevent the risk of uterine rupture during labor.

\section{Conclusion}

Myomectomy during pregnancy outside childbirth is possible but exceptional. There is an increased risk of bleeding that can darken the maternal-fetal prognosis. The risk-benefit ratio must be sufficiently evaluated before any operative indication.

\section{Conflict of Interest}

All the authors do not have any possible conflicts of interest.

\section{References}

[1] Dunson DB, Hill MC. Incidence cumulative élevée du léiomyome utérin chez les femmes noires et blanches: évidence échographique. J obstet Gynecol 2003; 188: 100-7.

[2] Levast F, Legendre G, Bouet PE, Sentilhes L. Prise en charge des myomes utérins pendant la grossesse. Gynecol Obstet Fertil. 2016 Juin; 44 (6): 350-4. Doi: 10.1016/j. gyobfe.2016.04.007. PMID: 27216952.

[3] Chauveaud-Lambling A, Fernandez H. Fibrome et grossesse. EMC-gynécologie obstétrique 2004; 5-047-R-10.

[4] Spyropoulou K, Kosmas I, Tsakiridis I, Mamopoulos A, Kalogiannidis I, Athanasiadis A, Daponte A, Dagklis T. Myomectomie pendant la grossesse: une revue systématique. Eur J Obstet Gynecol Reprod Biol. 2020 novembre; 254: 15-24. doi: 10.1016/j.ejogrb.2020.08.018. PMID: 32919229 .

[5] Celik C, Acar A, Nedim C, Kazim G, Cemalettin A. (2002) La myomectomie peut-elle être pratiquée pendant la grossesse ? Gynecol Obstet Invest 53: 79-83.

[6] Lopes P, Thibaud S, Simonnet R et al. Fibromes et grossesse: quels sont les risques? J Gynecol Obstet Biol Reprod 1999; 28: 772-77.

[7] Karlsen K, Schiøler Kesmodel U, Mogensen O, Humaidan P, Ravn P. Relation entre un diagnostic de fibrome utérin et le risque de résultats obstétricaux indésirables: une étude de cohorte. BMJ Open. 17 février 2020; 10 (2): e032104. Doi: 10.1136/bmjopen-2019-032104.PMID: 32071172. 
[8] Gávai M, Hupuczi P, Papp Z. Abdominal myomectomy as an alternative to hysterectomy: analysis of 504 cases, Orv Hetil. 2006 May 28; 147, 21: 971-8.

[9] Suwandinata FS, Gruessner SE, Omwandho CO, Tinneberg HR. Myomectomie préservant la grossesse: rapport préliminaire sur une nouvelle technique chirurgicale. The European Journal of Contraception \& Reproductive Health Care. 1 janvier 2008; 13 (3): 323-6.

[10] Lolis DE, Kalantaridou SN, Makrydimas G, Sotiriadis A, Navrozoglou I, Zikopoulos K, Paraskevaidis EA. Myomectomie réussie pendant la grossesse. Reproduction humaine. 1 août 2003; 18 (8): 1699-1702.

[11] Carolis SD, Fatigante G, Ferrazzani S, Trivellini C, Santis LD, et al. (2011) Myomectomie utérine chez les femmes enceintes. Diagnostic fotal Ther 16: 116-9.

[12] Farshad T, F, Morje M, Hurrell A, Gallaher C, Dawlatly B (2018) Myomectomie réussie au deuxième trimestre chez une patiente gravement malade. Crit Care Obst Gyne. Vol. 4 n 2: 5 . doi: $10.21767 / 2471-9803.1000158$.
[13] Barinov SV, Tirskaya YI, Lazareva OV, Kadcyna TV, Shamina IV, Medyannikova IV, Borisova AV, Frikel EA, Beznoshchenko GB. Pregnancy outcomes in women with large uterine fibroids. Journal of Maternal-Fetal and Neonatal Medicine, 2021; doi.org/10.1080/14767058.2021.1879044.

[14] Ezzedine D, Norwitz ER. Clin Obstet Gynecol. Les femmes atteintes de fibromes utérins présentent-elles un risque accru d'issue défavorable de la grossesse? 2016 mars; 59 (1): 119-27. Doi: 10.1097/GRF.0000000000000169. PMID: 26670833.

[15] Metwally M, Cheong YC, Horne AW. Traitement chirurgical des fibromes pour l'hypofertilité. Base de données Cochrane, Rev., 14 novembre 2012; 11: CD003857. Doi: 10.1002/14651858.CD003857.pub3. PMID: 23152222.

[16] Tulandi T, Murray C, Guralnick M. Adhesion formation and reproductive outcome after myomectomy and second-look laparoscopy. Obstet Gynecol 1993; 82 (2): 213-5.

[17] Wittich AC, Salminen ER, Yancey MK, Markenson GR. Myomectomie en début de grossesse. Médecine militaire. 2000 fév; 165 (2): 162-4. 